\section{La "solidaridad" de los créditos solidarios}

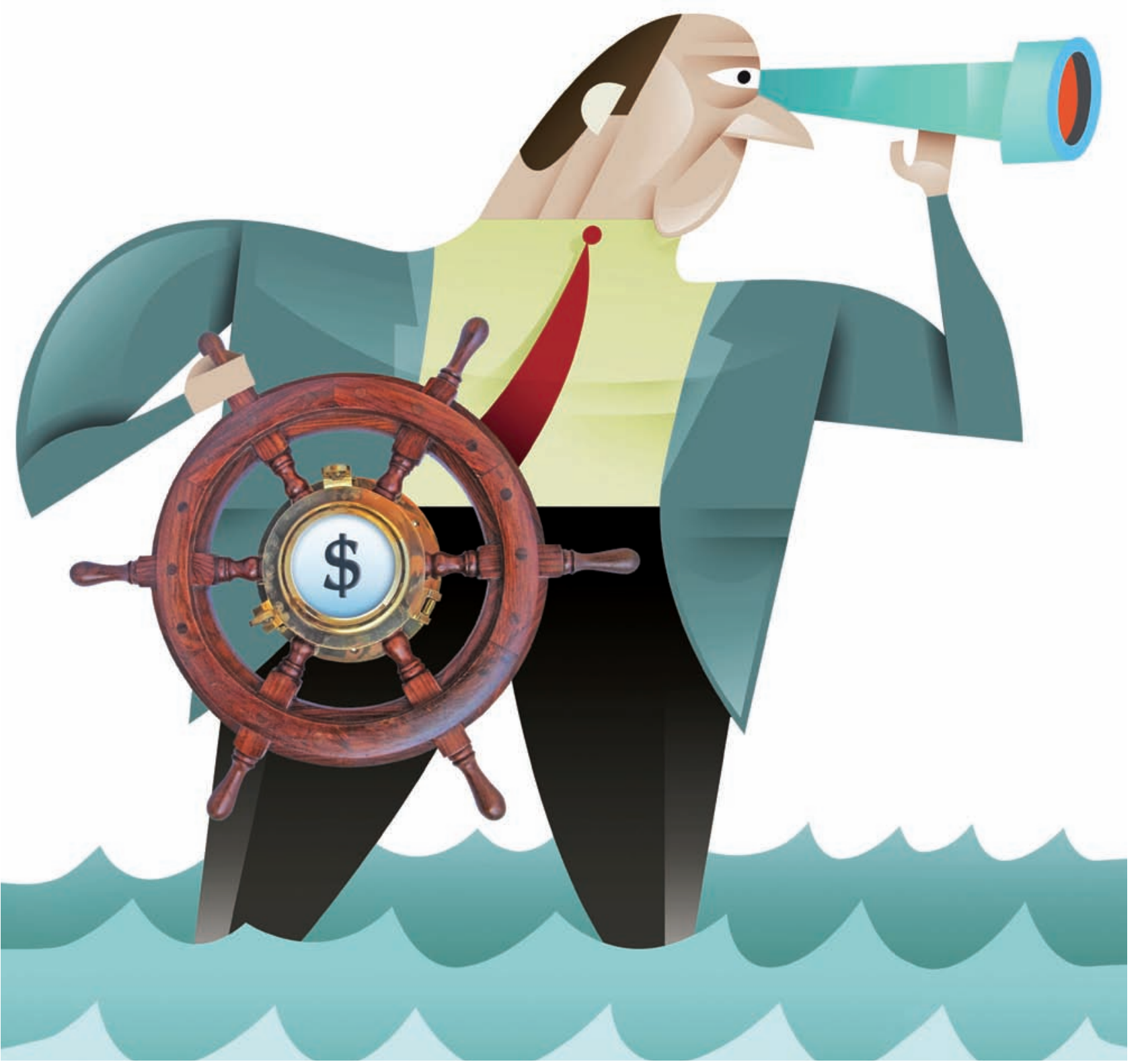

El 1 de junio de 2012 entró en vigencia la regulación que limita el nivel de endeudamiento permitido en los créditos otorgados por las Cajas de Compensación y Asignaciones Familiares (CCAF). Este cambio se enmarca en las discusiones parlamentarias y sociales sobre malas prácticas en las prestaciones de créditos solidarios, ya sea para sus pensionados y/o trabajadores afiliados. Por Lucas Navarro* $y$ Walter Nuñez $z^{* *}$
El 1 de junio de 2012 entró en vigencia la regulación que limita el nivel de endeudamiento permitido en los créditos
otorgados por las Cajas de Compensación otorgados por las Cajas de Compensación
y Asignaciones Familiares (CCAF). Este y Asignaciones Familiares (CCAF). Este
cambio se enmarca en las discusiones cambio se enmarca en las discusiones prácticas patentes en las prestaciones de créditos solidarios, ya sea para sus pensionados y/o trabajadores afiliados.

Las Cajas de Compensación son corporaciones de derecho privado, sin fines de lucro, cuyo objetivo es administrar las prestaciones de seguridad social. Están sometidas a la fiscalización y vigilancia de la Superintendencia de Seguridad Social (SUSESO)'. Las CCAF administran principalmente dos tipos de prestaciones de seguridad social: legales y de bienestar social. Las primeras estan vinculadas funciones propias del Estado, en la delegación de la administración de una parte ge los fondos de seguidad social, y las sedarios de consumo hipotecarios para sus afiliados ${ }^{2}$ Según la SUSESO, a I ño 2011 4.1 millones de trabajadores $y 1.4$ millones de pensionados se encontraban afiliados a las CCAF.

Por ley las Cajas de Compensación están facultadas para financiarse principalmente a través de la venta de servicios que prestan al Estado y a otras entidades $d e$ seguridad social, por comisiones por prestaciones a pensionados (2\% de la misma) y via oferta de creditos solidarios, ; siendo esta ultima la principal via de financiamiento que tienen estas instituciones para gas en los distintos ámbitos de sue otortencian efecto el número de préstamos otorgados a trabajadores y pensionados aumentó en $77 \%$ entre 2008 y 2011, gando a un total de 2.6 millones de préstamos, de los cuales $15 \%$ corresponden a pensionados. En cuanto al monto de los préstamos, hacia el año pasado era de 54 mil pesos.

El hecho que las CCAF presten a individuos a los que el resto del sistema ro no necesariamente lo haria, otorga a estas instituciones un cierto grado de poder de mercado que es necesario regular. Dos aspectos en los que se manifiesta esta tenmiento de los afiliados en riva endeudacomiento de los mismos bajo condiciones de tasas de interés, comisiones otros cargos elevados y poco claros.

En este contexto, toma significancia entonces el limite al nivel de endeudamiento interpuesto por la nueva requlación, la que responde, en parte, a las fuertes demandas materializadas entre enero y abril de este periodo del año anterior) ${ }^{4}$, y las distintas mociones parlamentarias en actual tramitación legislativas.

En efecto, indicaciones como el limite de endeudamiento equivalente a 8 veces a disminucion (le la ca pa finsion) liquida; de segun el nivel de remuneracion y la entrega mente a los beneficiados, van claramente en la dirección correcta, en cuanto buscan disminuir los potenciales abusos y endeudamiento excesivo de quienes están afiliados a estas instituciones $y$, por sobre todo, proteger a aquellos agentes pasivos que, al no calificar para pedir un préstamo en una institución bancaria tradicional, están en una posicion desfavorable respecto a alternativas.

Otras normas anunciadas en recientes circulares de la SUSESO son la reducción del periodo minimo de afiliación de 12 a 6 imposición de tasas de interés menores pensionados en relación a trabajadores. Sin embargo, es respecto a las tasas de interés por los créditos donde persisten racterística particular de amortización de deuda por planilla (que reduce el riesgo de incobrabilidad), intuitivamente las tasas de interés de las CCAF debiesen ser significativamente menores a las del resto de sistema. Si bien es cierto que estas institu- ciones no cuentan con las grandes fuentes de liquidez de un banco tradicional, ni dis(Conan por rissgos frente a sus afiliados (cobran tasas uniformes segun plazo

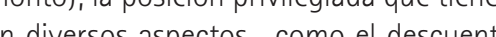
por planilla citado legitima el debate sobre las tasas de interés que cobran ¿Cuál es, $n$ última instancia la finalidad social que se busca alcanzar con estos créditos solidarios?

Las objeciones al nivel de endeudamiento y a las tasas de interés impuestas sponden a lo que se percibe como las minimas condiciones que a simple vista se observarian en un mercado competitivo. estanea, es importante reconsidera Comadero rol que cumplen las Cajas de Co de (T) ro aplicable a los créditos otorgados. Ellos ina es de créditos en dinero, pero no está ajo la jurisdicción de la Superintendencia e Bancos e Instituciones Financieras, organismo aparentemente idóneo en esta

Asimismo, si se trata de replicar los beercado competitivo, tamuar a qué incentivos responden hoy estas instituciones. Si bien la legislación garantiza que las CCAF reinviertan los excedentes de sus operaciones de financiamiento, estos recursos se desti-

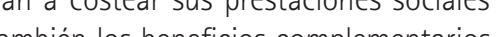

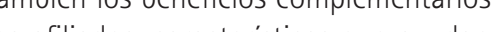
diferenciarlas entre si. De esta forma, auntue la competencia por intentar abtennuevos afiliados con servicios innovadores simple vista busca cautivar a potencia es clientes, los incentivos perversos por usufructuar de su principal vía de financiamiento (la oferta de créditos sociales) epercute negativamente en los beneficiarios al momento de acceder a un crédito. En ese sentido la SUSESO, ha anunciado medidas que obligan a las Cajas de Com- 
sobre estos beneficios adicionales a sus afiliados.

En definitiva, iniciativas como las anunciadas durante el ultimo año apuntan en y prevenir aquellas prácticas que atenta y prevenir aquellas practicas que atentan articulación de las Cajas de Compensación: ser el nexo entre las prestaciones en materia de seguridad social y quienes necesita más de estos beneficios: los desplazados por el sistema financiero tradicional.

No obstante, es importante seguir trabajando en estas iniciativas, dandole impulso a aquellas leyes que desde el Congreso intentan discutir y modificar las tasas de interés aplicadas a dichos créditos solidarios, replanteando la institución que rige y vigil su proceder en esta materia. Hay que reCajas de Compensación juegan en nuestra

especialmente a milias y otorgarle la importancia de que sistema funcione correctamente.

vease:_http://www.cajasdechile.cl/inicio/cajale-compensacion/preguntas-frecuentes
tas-frecuentes-creditos-hipotecarios $>$ (n)

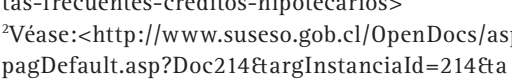
grCarpetald $=475 \mathrm{Etarg}$ Tree NodosAbiertos $=0.20$ odoSele 4575 CtargRegistroldd $1763>$
Ley N 18.833 , Estatuto General de las Cajas de Ley N $N^{\circ} 18.833$, Estatuto General de las Cajas
Compensacion. Véase:_http://www.suseso.cl/Open News/as /

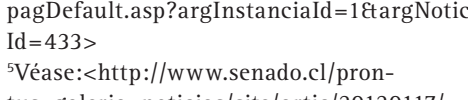

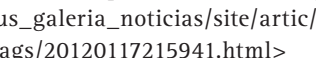
Wease: hhttp: ://www.susesoo.cl/open News/asp/ anciald=1 Itarg Notici

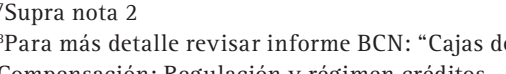

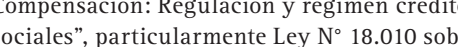
créditos en dinero.

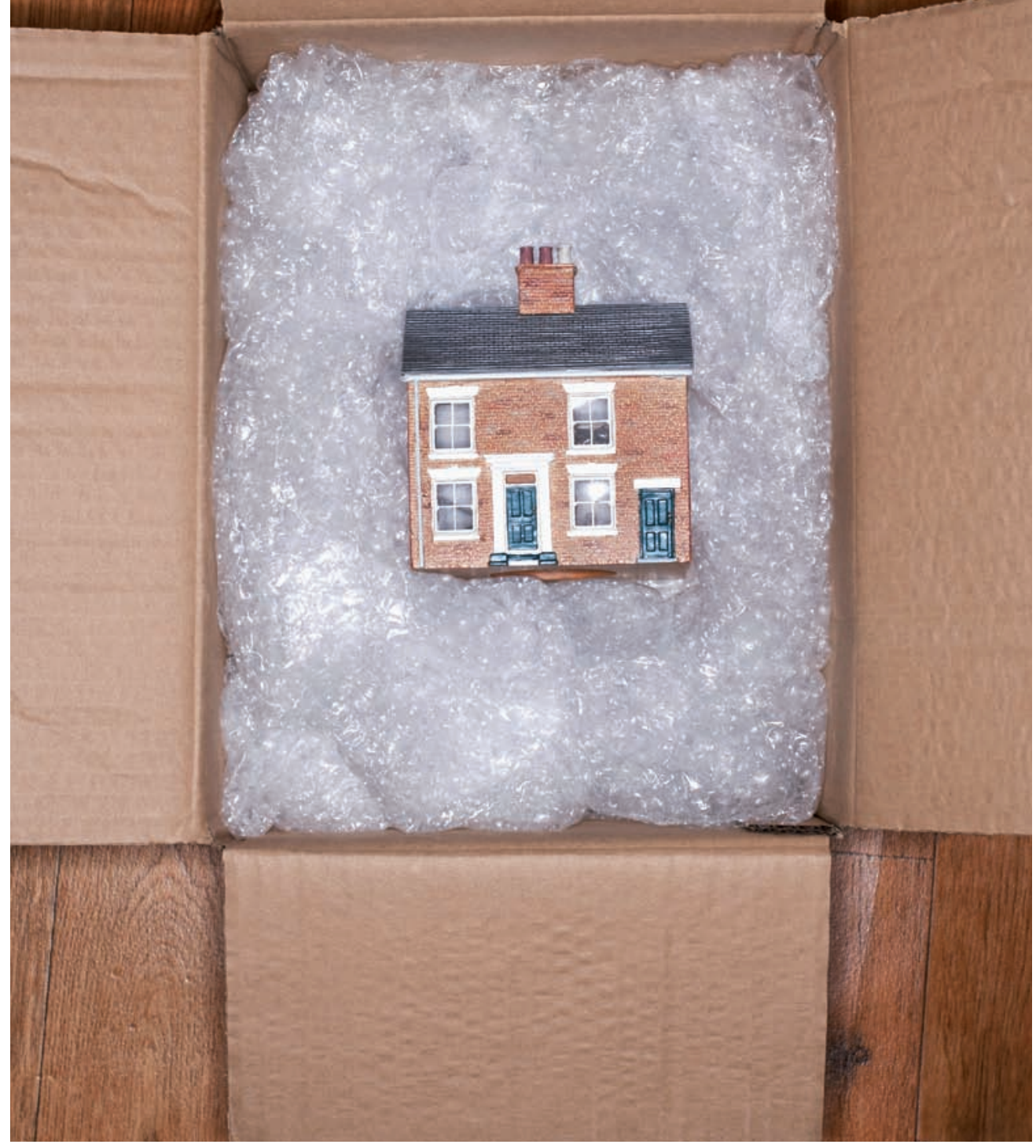

\section{¿Existe burbuja en el mercado inmobiliario?}

Por Pablo González*

Estados Unidos

Mucho se ha hablado sobre la probable existencia de una burbuja en el sector inmobiliario. Los argumentos en pro o en contra de este tema se han basado en observaciones de datos parciales, ya que es muy difíicil el acceso a datos recolectados en forma agregada. Entre estos argumentos incluso se mezclan elementos estructurales con otros coyunturales, algunos de los cuales pre-existian años atrás.

Es importante comprender que la existencia de una burbuja no puede ser determinada solo hasta que ésta explota. Una burbuja no es simplemente el incremento acelerado de precio de un activo, sino que, se reconoce porque esos mismo precios retornan a un nive sustancialmente menor acorde con condiciones reales de la economía y del mercado en particular de ese activo. La literatura económica reconoce las condiciones que han secuencias generadas para la economi pero poco hay respecto a predicciones. En general, estos cambios bruscos en precios no debieran ser un problema, salvo cuando el incremento inicial del precio del activo genere una "sensación de mayor riqueza en las personas que lo poseen, permitiéndoles incrementar sus consumos en base a crédito. En el caso de que se revele la existencia de la burbuja con precios que se ma financiero puede tener problemas para recuperar los préstamos, llegando a presentar problemas de solvencia que podria hacer colapsar al resto de la economía.

En el caso especifico del mercado a nos ocupa, es importante recordar que e inmueble construye parte de la riqueza de una persona y por lo tanto es un stock, un bien durable. Su consumo no es instantáneo, sino que puede prestar servicios. Por estos servicios hay una valoración que llamamos arriendo. Obviamente, arriend y precio del inmueble están vinculados en forma directa. Si los arfiendos suben, los res y por do tanto es precio sube tambie En y mismo sentido, si los precios de las viviendas bajan, observariamos arriendos más baratos.

Pero si los precios de las viviendas van al alza, la producción de éstas se ve estimulada. La construcción se acelera, se incrementa el stock de inmuebles, lo que lleva paulatinamente a una normalizaciò del precio, nuevamente por el incremento del stock disponible.

Con estas relaciones en mente podemos analizar los distintos argumentos que se han estado escuchando en el último an a favor o en contra de la existencia de un burbuja, teniendo en cuenta además, los internacionales 2008/09 y el terremoto de febrero de 2010 .

La industria sostiene razonablemente que ha existido un crecimiento de la demanda que estuvo contenida por la crisis en forma precautoria. Si a esto se suma reducción brusca del stock por efectos de terremoto, es lógico que exista una subida en los precios. Tal como se explica anteriormente, la produccion responde a los precios. El Índice Mensual de Actividad de Pero a nivel agregado no parece ser algo la Construcio Cámara Chilena de la Construcción) se ha (a) del IMACEC desde marzo del 2010. La disponibilidad futura de un nueontecio y la desamulación de demanda tina en los precios que no tendría relación con la existencia de una burbuja. Esta baja quizás, no se presente en algunas comunas especificamente aquellas Mapor oriente de Santiago, La Florida ciando cambios en demandas rar evidencomo parece haber sucedido en el relativo entre departamentos y casas luego del terremoto. Otros argumentos como cercanía a colegios o clubes, tiempos de traslados crecimiento demográfico, restricciones a uso del suelo y similares deben ser descartados como factores dado que pre-existian años atras y ya justificaban diferenciales de precios por barrios entonces. No puede los precios en la actualidad.

Entre los argumentos que intenton descartar una burbuja se ha mencionado el encarecimiento de los materiales de la construcción. Sin embargo, en base a inEstución elaborada por la Gerencia de forme MACh № 35 el "indice de Costos de Edificación ha estado aumentando a tasas anuales del orden del 3 a $4 \%$ en los últimos cinco meses, lo que constituye un ritmás bajo en relaciôn con lo acontecido Sl encarecimiento de los costos laborales (consistente con la y un Indice de Costos para Materiales se ha desacelerado incluso llegando a tasas negativas en los últimos meses. Este último punto puede ser reflejo de una reducción de las presiones de demanda interna por reconstrucción y la evolución de los dos internacionales en respuesta a la crisis internacional.

En definitiva, lo que es evidente es una fuerte alza en los precios en comunas determinadas, pero sobre lo cual no podemos discernir si corresponden a cambios actuales en preferencias o a una compeencia por plusvalía basada en la creencia de cambios futuros en esas preferencias. preocupante aún

mencionó el Banco Centra comienzos del mes de junio, los índices e precios de los inmuebles (estratificado yedonico) rados del 2\% real anual promedio en los a Cos dipe alededor de $80 \%$ entre los crédias tos covidencia recabada por el INE (de mayor cobertura y representatividad que Otras fuentes) para la elaboración del IPC respecto a la evolución del precio de los arriendos, los cuales están en concordancia con los números anteriores, reflejando una leve mejora real sin quiebre de tendencia significativo.

El Banco Central alertó además que es mportante que los deudores y prestamistas internalicen que las alzas de precio recientes no aseguran alzas en el futuro" En este sentido, el hecho de que el precio de las viviendas se haya mantenido estate como proporcion del ingreso, es un persodor de que enta gran mayoria de las precio se vincula directamente con arrienestaria manteniendo la proporción caso, si las inversiones inmobiliarias sectorizadas ven caer el precio en el futuro podrá ser solo una mala apuesta de esos inversores, siempre y cuando no constie créditos otorgados por las instituciones inancieras.
Decano: Jorge Rodríguez
conominynegocios uahurtado cl/observetoto Producción OE: C
Periodismo UAH. gasto mensual en vivienda. En todo 